\title{
Adaptive evolution of the vertebrate skeletal muscle sodium channel
}

\author{
Jian Lü, Jianzhou Zheng", Qinggang Xu, Keping Chen and Chiyu Zhang \\ Institute of Life Sciences, Jiangsu University, Zhenjiang, Jiangsu, PR China
}

\begin{abstract}
Tetrodotoxin (TTX) is a highly potent neurotoxin that blocks the action potential by selectively binding to voltage-gated sodium channels $\left(\mathrm{Na}_{v}\right)$. The skeletal muscle $\mathrm{Na}_{v}\left(\mathrm{Na}_{v} 1.4\right)$ channels in most pufferfish species and certain North American garter snakes are resistant to TTX, whereas in most mammals they are TTX-sensitive. It still remains unclear as to whether the difference in this sensitivity among the various vertebrate species can be associated with adaptive evolution. In this study, we investigated the adaptive evolution of the vertebrate $\mathrm{Na}_{\mathrm{v}} 1.4$ channels. By means of the CODEML program of the PAML 4.3 package, the lineages of both garter snakes and pufferfishes were denoted to be under positive selection. The positively selected sites identified in the $p$-loop regions indicated their involvement in $\mathrm{Na}_{v} 1.4$ channel sensitivity to TTX. Most of these sites were located in the intracellular regions of the $\mathrm{Na}_{\mathrm{v}} 1.4$ channel, thereby implying the possible association of these regions with the regulation of voltage-sensor movement.
\end{abstract}

Key words: skeletal muscle voltage-gated $\mathrm{Na}\left(\mathrm{Na}_{\mathrm{v}} 1.4\right)$ channel, tetrodotoxin (TTX), positive selection, pufferfish, garter snake.

Received: May 24, 2010; Accepted: November 30, 2010.

\section{Introduction}

Tetrodotoxin (TTX) is a highly potent neurotoxin, first isolated from toxic pufferfishes in 1950 (Yokoo, 1950). For many years, these animals were considered to be the only source of this toxin. However, in 1964, it was also detected in California newts (Mosher et al., 1964), and later, in a large variety of animal species, including goby fishes, starfishes and frogs (Miyazawa and Noguchi, 2001). It was further demonstrated that the accumulation in pufferfishes and other animals could be attributed to their food chain starting from TTX-producing marine bacteria, rather than from de novo synthesis (Miyazawa and Noguchi, 2001).

Voltage-gated $\mathrm{Na}^{+}$channels play an important role in regulating the generation and propagation of action potentials, in response to electrical excitability throughout nerves, muscles and the heart (Marban et al., 1998). They contain four homologous domains (DI - DIV), each of which with six transmembrane segments (S1-S6), as well as a re-entrant (P-loop) between S5 and S6 (Stuhmer et al., 1989). TTX is able to block the current of sodium ions, especially by binding to voltage-gated $\mathrm{Na}^{+}$channels, thereby resulting in animal-death (Narahashi et al., 1967). The P-loop regions of the $\mathrm{Na}^{+}$channels are responsible for the selectivity of $\mathrm{Na}^{+}$ions. Residue mutations in these regions are able to affect TTX binding to $\mathrm{Na}^{+}$channels (Lipkind and Fozzard, 2000).

Send correspondence to Chiyu Zhang. Institute of Life Sciences, Jiangsu University, 301 Xuefu Road, Zhenjiang, 212013 Jiangsu, PR China. E-mail: zhangcy1999@ hotmail.com. \#These authors contributed equally to this work.
Therefore, the P-loop regions are considered to be crucial in avoiding TTX mediated animal death.

Pufferfishes can accumulate extremely high concentrations of TTX without any adverse effect. This resistance is attributed to TTX-resistant skeletal muscle $\mathrm{Na}^{+}\left(\mathrm{Na}^{+} 1.4\right)$ channels. Pufferfish normally eat a TTX-rich diet, thus sustaining a strong, long-term natural-selection pressure to drive the evolution of TTX resistance in $\mathrm{Na}^{+} 1.4$ channels, also a beneficial gain in their defense against natural enemies (i.e. predators) (Venkatesh et al., 2005). On the other hand, by preying on TTX-bearing newts, some North American garter snakes (Thamnophis sirtalis) might have been compelled to independently evolve resistance to the neurotoxin itself (Geffeney et al., 2002, 2005). In contrast, this did not occur in most mammals and other organisms, possibly due to the absence of the toxin in their diet. However, it remains unclear whether the difference in $\mathrm{Na}_{\mathrm{v}} 1.4$ channel sensitivity to TTX in non-mammalian vertebrates (e.g. pufferfish) and mammals is associated with adaptive evolution or not. In the present study, we used a robust codonsubstitution model in PAML package (Yang, 2007) to investigate the adaptive evolution of $\mathrm{Na}_{\mathrm{v}} 1.4$ channels in certain vertebrate species. Branch-site tests revealed that the $\mathrm{Na}_{\mathrm{v}} 1.4$ channels in garter snakes and pufferfish were under positive selection. Eight and five positively selected sites were identified in garter snake and pufferfish lineages, respectively. It is worthy of note that, regardless of the presence in either garter snakes or pufferfishes, most of the positively selected sites were located in the intracellular regions of the $\mathrm{Na}_{\mathrm{v}} 1.4$ channel, thereby implying that these re- 
gions play a crucial role in the adaptive evolution of the channel itself.

\section{Methods}

\section{Sequence analysis}

In order to investigate the adaptive evolution of skeletal muscle $\mathrm{Na}_{\mathrm{v}} 1.4$ channels, 19 complete gene sequences of these same channels from TTX-sensitive mammals, electric fishes and zebrafish, as well as TTX-resistant garter snakes and pufferfish, were retrieved from GenBank and Swiss-port. The sequence selection comprised three pufferfish sequences: Takifugu pardalis (Tp)(accession number: AB030482), Takifugu rubripes (Tr) (DQ221249), and Tetraodon nigroviridis (Tn) (DQ221251), four garter snakes: (AY851743 to AY851746) from Bear Lake (BL), Warrenton (War), Benton (Ben) and Willow Creek (WC), nine mammalians: Canis familiaris (cf) (XM_848303), Macaca mulatta (macaca) (XM_001116451), Mus musculus (mus) (NM_133199), Rattus norvegicus (Rn and RnSkM1) (NM_01317̄8 and Y17153), Homo sapiens (Hs and HsSkM1) (NM 000334 and AY212253), Bos taurus (Bos) (XR 028741), and Equus caballus (Ec) (NM_001081761), one zebrafish (NM_001039825), and two electric fish Sternopygus macrurus (Sm) (AF378144) and Electrophorus electricus (Ee) (X01119). Proteincoding sequences were aligned based on translated protein sequences using the Clustal $\mathrm{W}$ program implemented in MEGA 4 (Thompson et al., 1994). In order to gain an insight into evolutionary relationships, a phylogenetic tree based on the amino acid alignments was constructed by using the NJ (neighbor-joining) method implemented in MEGA 4.0 (Tamura et al., 2007), and the reliability of the tree was estimated using bootstrap method with 1000 replications (Felsenstein, 1985).

\section{Adaptive evolutionary analysis}

Maximum likelihood analysis was employed to detect adaptive evolution in $\mathrm{Na}_{\mathrm{v}} 1.4$ channels, using the CODEML program in the PAML 4.3 package, which has been proven to be a powerful tool for inferring positively selected sites (Zhang et al., 2005). Positive selection is generally measured by the rate-ratio of non-synonymous substitutions per non-synonymous site $(\mathrm{dN})$ to that of synonymous substitutions per synonymous site $(\mathrm{dS})(\omega=\mathrm{dN} / \mathrm{dS})$. The $\omega$ values of $>1,1$ and $<1$ indicate positive (diversifying) selection, random drift and negative (purifying) selection, respectively. Branch-site tests were employed to detect positive selection along various evolutionary lineages. In model $\mathrm{A}$, three $\omega$ ratios $\left(0<\omega_{0}<1, \omega_{1}=1, \omega_{2}>1\right)$ and 2 $\omega$ ratios $\left(0<\omega_{0}<1, \omega_{1}=1\right)$ were assigned to the foreground and background branches, respectively. The null model (model $\mathrm{A}^{\prime}$ ) was the same as model $\mathrm{A}$, but with a fixed $\omega_{2}=1$. To detect whether positive selection affects a small number of sites along the pufferfish lineage (branch a in Figure 1), the pufferfish lineage was set to be the foreground branch, and others to be the background branch in model A. The same process was then used to detect positive selection acting on the lineages of garter snakes and mammals, by assigning each of the two lineages in turn as the foreground branch.

\section{Results and Discussion}

\section{Evolution of $\mathrm{Na}_{\mathrm{v}} 1.4$ channel genes}

Invertebrate species only possess one or, at the most, two $\mathrm{Na}^{+}$channel genes, compared to the 9 in non-mammalian vertebrates and 10 in mammals (Lopreato et al., 2001). The greater number of these genes in the case of vertebrates, as a whole, came about by multiple gene duplication (Goldin, 2002; Novak et al., 2006). Within its respective gene family, the $\mathrm{Na}_{\mathrm{v}} 1.4$ channel has been well-studied. Mainly expressed in skeletal muscles, its chromosomal localization and evolutionary relationships are distant from the rest (Yu and Catterall, 2003). These skeletal-muscle $\mathrm{Na}_{\mathrm{v}} 1.4$ channels present species-specific sensitivity to TTX. In pufferfishes, they have evolved resistance to TTX, besides also serving, in certain species, as TTX-specific chemoreceptors when the toxin is imposed as a female pheromone (Venkatesh et al., 2005). Certain other nonmammalian vertebrates, such as North American garter snakes, have also developed $\mathrm{Na}_{\mathrm{v}} 1.4$ channel resistance to TTX throughout the long-term evolutionary process (Geffeney et al., 2005). Notwithstanding, in mammals and three other fishes, these channels have not developed this resistance, thus remaining very highly TTX sensitive.

A phylogenetic tree was constructed with MEGA 4.0 (Tamura et al., 2007), in order to investigate the evolutionary relationships of $\mathrm{Na}_{\mathrm{v}} 1.4$ channels among vertebrates. Four groups of sequences from pufferfish, three other fishes, garter snakes and mammals formed four well-sup-

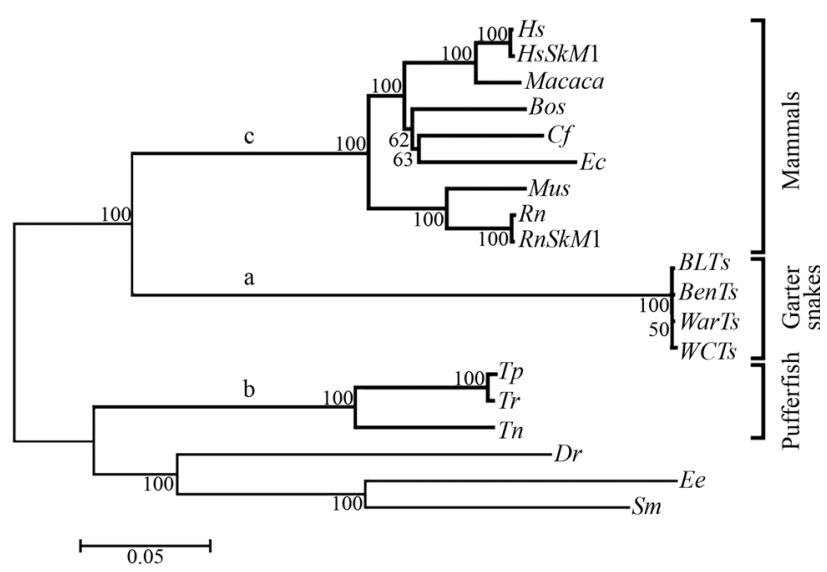

Figure 1 - Phylogenetic tree of $\mathrm{Na}_{\mathrm{v}} 1.4$ channel genes in vertebrates. The phylogenetic tree was constructed with MEGA 4.0 using the Neighbor-Joining method. The reliability of the tree was evaluated by the bootstrap approach with 1000 replications. 
ported clades in the tree (with bootstrap values of 100\%) (Figure 1). The $\mathrm{Na}_{\mathrm{v}} 1.4$ channels in the mammalian and the three fish branches were sensitive to TTX, in contrast to the pufferfish and garter snake, which were resistant, thereby indicating that the tree topology was consistent with both the functional and species divergence therein. The difference in sensitivity to TTX implied the existence of certain crucial residual sites contributing to functional divergence among different vertebrates. Therefore, it was inferred that the gain in resistance to TTX in the $\mathrm{Na}_{\mathrm{v}} 1.4$ channels of pufferfishes and garter snakes was due to adaptation to a new environment, thus bettering the chances of preying on TTX-bearing organisms.

\section{Test of positive selection and identification of positively selected sites}

Darwinian natural selection foments protein evolution by accumulating advantageous mutations for adaptation to a changing environment. During vertebrate evolution, the $\mathrm{Na}_{\mathrm{v}} 1.4$ channels in pufferfishes and garter snakes developed a resistance to TTX (Geffeney et al., 2002, 2005; Venkatesh et al., 2005). To address whether this specific gain could be associated with positive selection, the maximum likelihood model in the CODEML program of the PAML 4.3 package was used to detect positive selection acting on the $\mathrm{Na}_{\mathrm{v}} 1.4$ channel (Yang, 2007). The branch-site model was applied to estimating variation in the pattern of substitution across sites along pufferfish (branch a), garter snake (branch b), and mammalian (branch c) lineages (Figure 1). The results are shown in Table 1.

The results revealed that signs of positive selection were detected in groups of garter snakes, pufferfishes and mammals $(p<0.001)$. In the garter snake lineage, $3.5 \%$ of the $\mathrm{Na}_{\mathrm{v}} 1.4$ channel sites were identified as having undergone strong positive selection, with $\omega=504.78$. At the level of Bayes empirical Bayes (BEB) posterior probability = $0.95,8$ positively selected sites were identified (Table 1 ). For the pufferfish lineage, $2 \%$ of the $\mathrm{Na}_{\mathrm{v}} 1.4$ channel sites were identified, with $\omega=131.46$. Five specific sites were identified in this branch at $\mathrm{p}>0.95$ (Table 1). As regards mammalian lineage, $2.2 \%$ of the $\mathrm{Na}_{\mathrm{v}} 1.4$ channel sites were identified, with $\omega=46.97$. From these results, it can be inferred that positive selection has played a crucial role in the evolution of skeletal muscle $\mathrm{Na}_{\mathrm{v}} 1.4$ channels.

\section{Location of positively selected sites}

The sodium channel is composed of four domains (I-IV), each consisting of six transmembrane segments (S1-S6) (Figure 2). The S4 transmembrane $\alpha$-helical, possessing many positively charged residues, is the voltage

Table 1 - Maximum likelihood (ML) estimates with the branch-site model for the $\mathrm{Na}_{\mathrm{v}} 1.4$ channel gene.

\begin{tabular}{|c|c|c|c|c|c|c|c|c|}
\hline Models & df & $\begin{array}{l}\text { Parameters under null } \\
\text { model }\end{array}$ & $\begin{array}{l}\text { Parameters under alter- } \\
\text { native model }\end{array}$ & $\ln L_{0}\left(\ln L_{1}\right)$ & $2 \Delta l$ & p-value & $\begin{array}{l}\text { Positively se- } \\
\text { lected sites }\end{array}$ & $\begin{array}{l}\text { BEB prob. of } \\
\text { sites }\end{array}$ \\
\hline \multicolumn{9}{|c|}{ Branch-site model A } \\
\hline \multirow{5}{*}{$\begin{array}{l}\text { Pufferfish group } \\
\text { as foreground } \\
\text { MA' vs. MA }^{\text {' }}\end{array}$} & \multirow[t]{5}{*}{1} & \multirow{5}{*}{$\begin{array}{l}\mathrm{MA}^{\prime}\left(\text { fix } \omega_{2}=1\right) \\
p_{0}=0.837, \omega_{0}=0.062 \\
p_{1}=0.137 \\
\left(p_{2 \mathrm{a}}+p_{2 \mathrm{~b}}=0.026\right)\end{array}$} & \multirow{5}{*}{$\begin{array}{l}\mathrm{MA} \\
p_{0}=0.844, \omega_{0}=0.063 \\
\omega_{2}=131.46 \\
p_{1}=0.136 \\
\left(p_{2 \mathrm{a}}+p_{2 \mathrm{~b}}=0.020\right)\end{array}$} & \multirow{5}{*}{$\begin{array}{c}-33818.74 \\
(-33808.45)\end{array}$} & \multirow[t]{5}{*}{20.58} & \multirow[t]{5}{*}{$<0.001$} & 1207 & 0.956 \\
\hline & & & & & & & 1425 & 0.958 \\
\hline & & & & & & & 1638 & 0.974 \\
\hline & & & & & & & 1654 & 0.979 \\
\hline & & & & & & & 1771 & 0.988 \\
\hline \multirow{10}{*}{$\begin{array}{l}\text { Garter snake } \\
\text { group as fore- } \\
\text { ground } \mathrm{MA}^{\prime} v s \text {. } \\
\text { MA }\end{array}$} & \multirow[t]{10}{*}{1} & \multirow{10}{*}{$\begin{array}{l}\mathrm{MA}^{\prime}\left(\text { fix } \omega_{2}=1\right) \\
p_{0}=0.840, \omega_{0}=0.062 \\
p_{1}=0.133 \\
\left(p_{2 \mathrm{a}}+p_{2 \mathrm{~b}}=0.027\right)\end{array}$} & \multirow{10}{*}{$\begin{array}{l}\text { MA } \\
p_{0}=0.840, \omega_{0}=0.063 \\
\omega_{2}=504.78 \\
p_{1}=0.125 \\
\left(p_{2 \mathrm{a}}+p_{2 \mathrm{~b}}=0.035\right)\end{array}$} & \multirow{10}{*}{$\begin{array}{c}-33814.66 \\
(-33790.68)\end{array}$} & \multirow[t]{10}{*}{47.96} & \multirow[t]{10}{*}{$<0.001$} & 60 & 0.992 \\
\hline & & & & & & & & \\
\hline & & & & & & & & \\
\hline & & & & & & & 928 & 0.953 \\
\hline & & & & & & & 933 & 0.961 \\
\hline & & & & & & & 951 & 0.989 \\
\hline & & & & & & & 1005 & 0.975 \\
\hline & & & & & & & 1336 & 0.951 \\
\hline & & & & & & & 1805 & 0.966 \\
\hline & & & & & & & 1818 & 0.997 \\
\hline \multirow{5}{*}{$\begin{array}{l}\text { Mammalian } \\
\text { group as fore- } \\
\text { ground } \mathrm{MA}^{\prime} v s \text {. } \\
\text { MA }\end{array}$} & \multirow[t]{5}{*}{1} & \multirow{5}{*}{$\begin{array}{l}\mathrm{MA}^{\prime}\left(\text { fix } \omega_{2}=1\right) \\
p_{0}=0.845, \omega_{0}=0.063 \\
p_{1}=0.137 \\
\left(p_{2 \mathrm{a}}+p_{2 \mathrm{~b}}=0.028\right)\end{array}$} & MA & \multirow{5}{*}{$\begin{array}{l}-33820.17 \\
(-33806.53)\end{array}$} & \multirow[t]{5}{*}{27.28} & \multirow[t]{5}{*}{$<0.001$} & 358 & 0.973 \\
\hline & & & $p_{0}=0.846, \omega_{0}=0.063$ & & & & & \\
\hline & & & $\omega_{2}=46.97$ & & & & 485 & 0.968 \\
\hline & & & $\begin{array}{l}p_{1}=0.132 \\
\left(p_{2 \mathrm{a}}+p_{2 \mathrm{~b}}=0.022\right)\end{array}$ & & & & 486 & 0.985 \\
\hline & & & & & & & 1201 & 0.986 \\
\hline
\end{tabular}

${ }^{a}$ The numbering of amino acids is according to the rat $\mathrm{Na}_{\mathrm{v}} 1.4$ protein sequence (AAA41682). 
sensor. Four extracellular loops (the p-loop between the S5 and S6 segments of four domains) dip down into the membrane to form the mouth of the pore by facing each other. The p-loops are responsible for ion selectivity of the channel (i.e. preference for $\mathrm{Na}^{+}$ions). The $\mathrm{S} 4$ segment can initiate conformational changes, thereby leading to the movement of S5 and S6 segments, both of which control the opening and closing of the channel (Marban et al., 1998). TTX binds to the outer vestibule of the pore, which is composed of amino acid residues in re-entrant P-loops (Figure 2). TTX binding occludes the pore, thereby preventing the extracellular entry of $\mathrm{Na}^{+}$ions. The TTXbinding region covers the amino acid residues located in and between two rings of the P-loops. The outer ring is formed by residues E403 in domain I, E758 in domain II, M1240 in domain III and D1532 in domain IV, while the inner ring includes residues D400 in domain I, E755 in domain II, K1237 in domain III and A1529 in domain IV (rat Nav1.4, AAA41682) (Soong and Venkatesh, 2006). The amino acid changes occurring in the TTX-binding region, especially in sites at 401 and 758 , have been demonstrated to play crucial roles in sensitivity to TTX.

Positive selection generally represents a functional adaptation. To investigate the potential relationship of positive selection to gained $\mathrm{Na}_{\mathrm{v}} 1.4$ channel resistance to TTX in pufferfish and garter snakes, the positively selected sites identified in rat $\mathrm{Na}_{\mathrm{v}} 1.4$ channels were mapped (Figure S1). All the 8 positively selected sites identified in the garter snake lineage were located in the intracellular regions of the $\mathrm{Na}_{\mathrm{v}} 1.4$ channel. Of the 5 sites in the pufferfish lineage, three $(60 \%)$ were located in intracellular regions, one in the P-loop of domain III, and one in the transmembrane region. Two positive sites in mammalian lineage were located in the P-loops of domain I and IV, and another two in the intracellular regions. Worthy of note, the positively selected sites in the p-loops were located outside the two rings of p-loops.

Despite the importance of the two rings of amino acid residues in the TTX-binding region in TTX sensitivity, they are not the sole determinant of the resistance to TTX. A compelling example is the mammalian cardiac $\mathrm{Na}_{\mathrm{v}} 1.5$ channel, which has the same two rings of amino acid residues in this specific binding region as do mammalian skeletal muscle $\mathrm{Na}_{\mathrm{v}} 1.4$ and other $\mathrm{Na}_{\mathrm{v}}$ channels. The cardiac channel appears to be TTX-resistant, whereas the remainder are sensitive to much lower amounts of TTX (Soong and Venkatesh, 2006). Therefore, the location of positively selected site (1207) in the p-loops of the $\mathrm{Na}_{\mathrm{v}} 1.4$ channel gives to understand a potential association with gaining TTX resistance in the pufferfish lineage, in spite of it not covering the TTX-binding region itself.

Environmental change, especially in diet, is one of the major driving forces in organismic evolution. Where the diet often includes poison (e.g. TTX), strong survival stress compels animals to develop the adequate resistance. In the case of pufferfishes, this occurred as regards TTX in response to their diet generally including TTXbearing organisms, such as starfish, gastropods and shrimps (Miyazawa and Noguchi, 2001). In certain populations of North American garter snakes that feed on tetrodotoxic newts, strong survival pressure compelled them to evolve resistance of the $\mathrm{Na}_{\mathrm{v}} 1.4$ channel to TTX as a means of adaptation to a toxin bearing $\operatorname{diet}$ (Geffeney et al., 2002). The higher $\omega$ values in pufferfishes and gar-

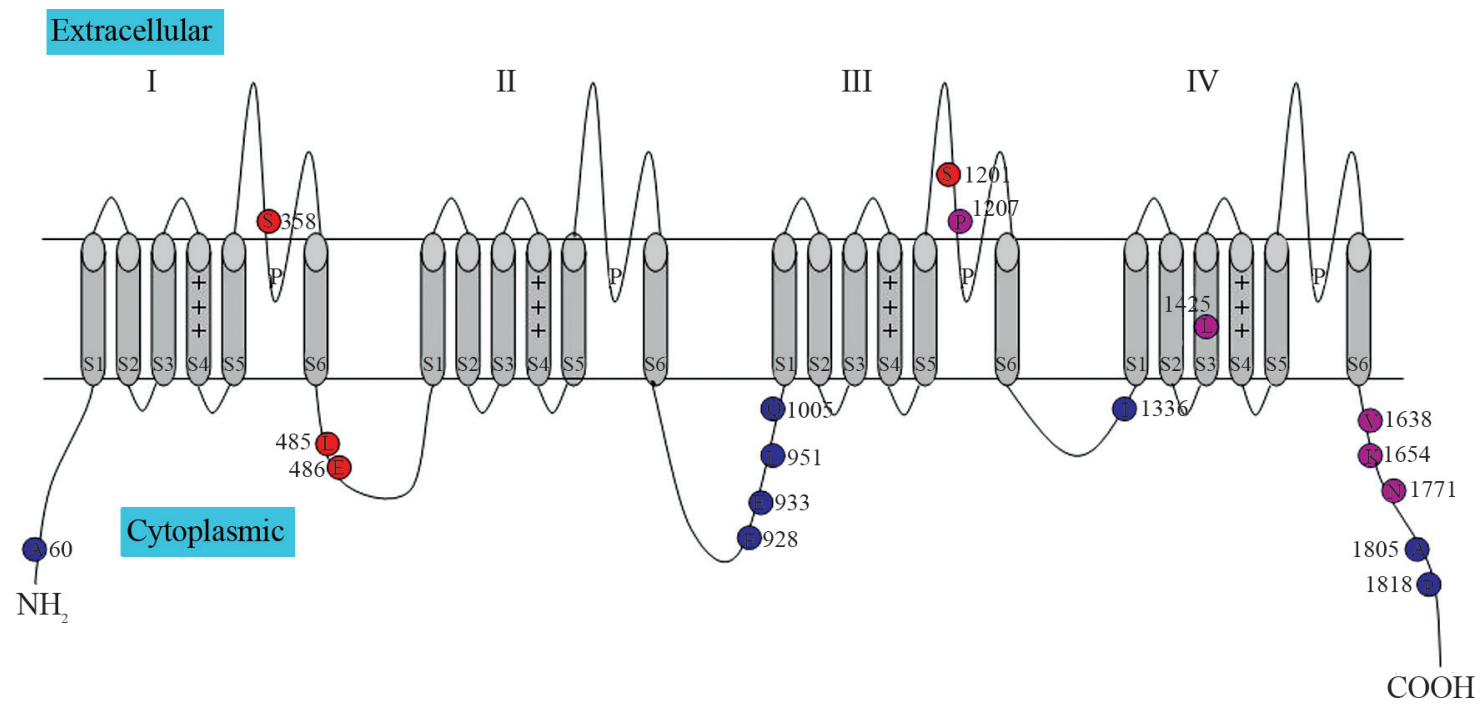

Figure 2 - Two-dimensional structure of the rat $\mathrm{Na}_{\mathrm{v}} 1.4$ channel. A sodium channel is composed of four domains (I - IV), each consisting of six transmembrane segments (S1-S6). The $\alpha$-helical S4 segment, which possesses many positive charges, is the voltage sensor. The P-loops between the S5 and S6 segments of each domain face each other, thus forming a pore that is the outer mouth of the channel. The loop between domains III and IV is the inner mouth of the channel. Cylinders indicate transmembrane $\alpha$-helices, whereas lines represent the hydrophilic portions of the channel. Pink, blue and red amino acids represent positively selected sites identified in the pufferfish, garter snake and mammalian lineages, respectively (for detail see Figure 1). Numbering of the amino acids is according to the rat $\mathrm{Na}_{\mathrm{v}} 1.4$ protein sequence (AAA41682). 
ter snakes than in mammals, clearly indicate that certain beneficial nonsynonymous mutations became fixed (accumulated) through Darwinian natural selection, for them to so possess this specific resistance. In most mammals, their natural diets do not include TTX-bearing organisms, whereby their $\mathrm{Na}_{\mathrm{v}} 1.4$ channels became functionally more constrained.

In pufferfish, one site in the $\mathrm{P}$-loop region might be associated with the gain of TTX-resistance by $\mathrm{Na}_{\mathrm{v}} 1.4$ channels. Three sites, located in cytoplasmic regions, could possibly be associated with $\mathrm{Na}^{+}$channel activation, by influencing internal conformation (Figure 2) (Marban et al., 1998; Yu and Catterall, 2003). However, the site at 1425 is located within the S3 transmembrane $\alpha$-helical of domain IV, and thus probably not associated with TTX-binding (Figure 2). In the garter-snake lineage, all positively selected sites of the $\mathrm{Na}_{\mathrm{v}} 1.4$ channel were detected in cytoplasmic regions, especially in the linker regions between domains II and III. Previous studies showed that the linker between domains III and IV mediated the quick inactivation of $\mathrm{Na}_{\mathrm{v}}$ channels (Rohl et al., 1999). The bias of positively selected sites occurring in the intracellular regions implied an association with TTX-blocking action. Therefore, the large amino-terminal and carboxy-terminal tails, as well as II-III linker may contribute to activating $\mathrm{Na}^{+}$channels by influencing internal conformation (Marban et al., 1998; Yu and Catterall, 2003). More positively selected sites occurring in these inner linkers possibly implied activity as gating inner controllers of voltage-sensor movement, thereby contributing to the activation of $\mathrm{Na}^{+}$channels. In the mammalian lineage, four sites were detected as having undergone positive selection. Due to the absence of TTX in the mammalian diet, positive selection acting on the mammalian $\mathrm{Na}_{\mathrm{v}} 1.4$ channel might infer a novel functional divergence.

In summary, the adaptive evolution of the $\mathrm{Na}_{\mathrm{v}} 1.4$ channel in vertebrates was investigated. Phylogenetic analyses showed these channels to be well divided into four large clades, pufferfishes, other fishes, garter snakes and mammals. The lineages of both garter snakes and pufferfishes were detected to have gone through stronger positive selection. Eight and five positively selected sites were identified in the garter snake and pufferfish lineages, respectively. The location of these sites in the $\mathrm{Na}_{\mathrm{v}} 1.4$ channels implied that some were associated with the gain of $\mathrm{Na}_{\mathrm{v}} 1.4$ channel resistance to TTX, as well as potential adaptation to a TTX-containing environment. Furthermore, it was noted that most of the positively selected sites, regardless of being in garter snakes or pufferfish, were located in the intracellular regions of the $\mathrm{Na}_{\mathrm{v}} 1.4$ channel, making an inference of potential roles in voltage-sensor movement.

\section{Acknowledgments}

The study was supported by grants from the "topnotch personnel"' project of Jiangsu University.

\section{References}

Felsenstein J (1985) Confidence limits on phylogenies: An approach using the bootstrap. Evolution 39:783-791.

Geffeney S, Brodie Jr ED, Ruben PC and Brodie 3rd ED (2002) Mechanisms of adaptation in a predator-prey arms race: TTX-resistant sodium channels. Science 297:1336-1339.

Geffeney SL, Fujimoto E, Brodie 3rd ED, Brodie Jr ED and Ruben PC (2005) Evolutionary diversification of TTX-resistant sodium channels in a predator-prey interaction. Nature 434:759-763.

Goldin AL (2002) Evolution of voltage-gated $\mathrm{Na}(+)$ channels. J Exp Biol 205:575-584.

Lipkind GM and Fozzard HA (2000) KcsA crystal structure as framework for a molecular model of the $\mathrm{Na}(+)$ channel pore. Biochemistry 39:8161-8170.

Lopreato GF, Lu Y, Southwell A, Atkinson NS, Hillis DM, Wilcox TP and Zakon HH (2001) Evolution and divergence of sodium channel genes in vertebrates. Proc Natl Acad Sci USA 98:7588-7592.

Marban E, Yamagishi T and Tomaselli GF (1998) Structure and function of voltage-gated sodium channels. J Physiol 508:647-657.

Miyazawa K and Noguchi T (2001) Distribution and origin of tetrodotoxin. Toxin Rev 20:11-33.

Mosher HS, Fuhrman FA, Buchwald HD and Fischer HG (1964) Tarichatoxin-tetrodotoxin: A potent neurotoxin. Science 144:1100-1110.

Narahashi T, Haas HG and Therrien EF (1967) Saxitoxin and tetrodotoxin: Comparison of nerve blocking mechanism. Science 157:1441-1442.

Novak AE, Jost MC, Lu Y, Taylor AD, Zakon HH and Ribera AB (2006) Gene duplications and evolution of vertebrate voltage-gated sodium channels. J Mol Evol 63:208-221.

Rohl CA, Boeckman FA, Baker C, Scheuer T, Catterall WA and Klevit RE (1999) Solution structure of the sodium channel inactivation gate. Biochemistry 38:855-861.

Soong TW and Venkatesh B (2006) Adaptive evolution of tetrodotoxin resistance in animals. Trends Genet 22:621-626.

Stuhmer W, Conti F, Suzuki H, Wang XD, Noda M, Yahagi N, Kubo H and Numa S (1989) Structural parts involved in activation and inactivation of the sodium channel. Nature 339:597-603.

Tamura K, Dudley J, Nei M and Kumar S (2007) MEGA4: Molecular Evolutionary Genetics Analysis (MEGA) software v. 4.0. Mol Biol Evol 24:1596-1599.

Thompson JD, Higgins DG and Gibson TJ (1994) CLUSTAL W: Improving the sensitivity of progressive multiple sequence alignment through sequence weighting, position-specific gap penalties and weight matrix choice. Nucleic Acids Res 22:4673-4680.

Venkatesh B, Lu SQ, Dandona N, See SL, Brenner S and Soong TW (2005) Genetic basis of tetrodotoxin resistance in pufferfishes. Curr Biol 15:2069-2072.

Yang Z (2007) PAML 4: Phylogenetic analysis by maximum likelihood. Mol Biol Evol 24:1586-1591.

Yokoo A (1950) Chemical studies on pufferfish toxin (3) - Separation of spheroidine. Nippon Kagaku Zasshi 71:590592. 
Yu FH and Catterall WA (2003) Overview of the voltage-gated sodium channel family. Genome Biol 4:e207.

Zhang J, Nielsen R and Yang Z (2005) Evaluation of an improved branch-site likelihood method for detecting positive selection at the molecular level. Mol Biol Evol 22:2472-2479.

\section{Supplementary Material} ticle:
The following online material is available for this ar-
Figure S1 - Alignment of the complete sequence of Nav1.4 channels in pufferfishes, garter snakes and mammals.

This material is available as part of the online article from http//scielo.br/gmb.

Associate Editor: Louis Bernard Klaczko

License information: This is an open-access article distributed under the terms of the Creative Commons Attribution License, which permits unrestricted use, distribution, and reproduction in any medium, provided the original work is properly cited. 
garter snakes

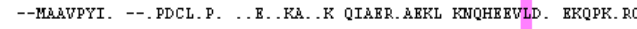

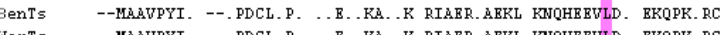
WarTs

Bos

Rus

HsSkM1

Hs

Macac

Cf
Bc
Dn

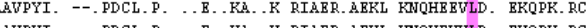

MARASLPTVW . L. PBSL. P. . B. A DV. B. AROL RNKOMBI..T BO--K. RS.M

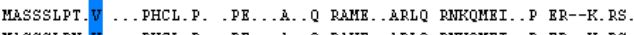

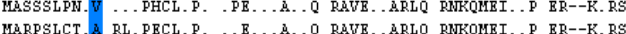

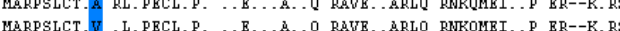

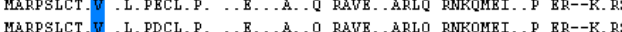

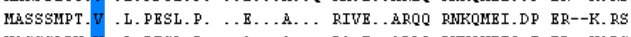

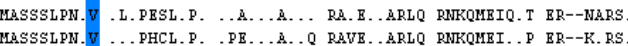

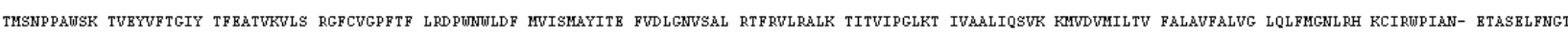

garter snakes

BLTs WarTs

WCTs

Bos

RnSkM1

HsSkMI
Hs
Macaca
Cf

$c f$

$\mathrm{BC}$

$\mathrm{Tr}_{\mathrm{Tr}}$

Dr

BLTs

Bents

WarT

Bos

Mus

HSSkML

$\mathrm{Hs}$

Maca

$\mathrm{Rn}$

$T_{p}$

garter snakes

BLTs

Bents

WarTs

Mus

RnSkM1

$\mathrm{Hs}$

Macaca

Cf

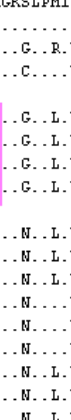

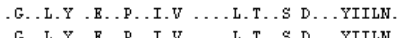

L.T.S D...YYILW

L.T..S D...YIILN

P..I.I

L..Y.S DK...I.LIN.

L..Y.S DK...I. LN.

VI.

L..Y.S MR...I. IN.

L..Y.S NK...I. LN.

P.VI. I

P.VI.

L.Y.S DRT..... LN

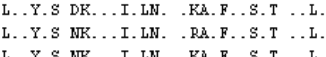

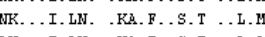

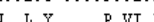

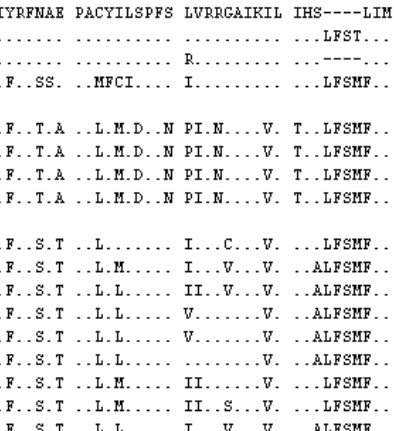

IM ITILSNCVFM

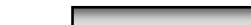

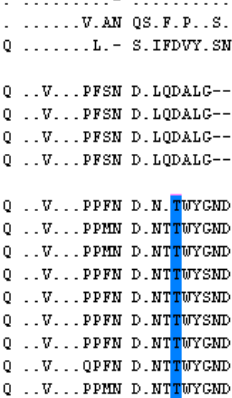

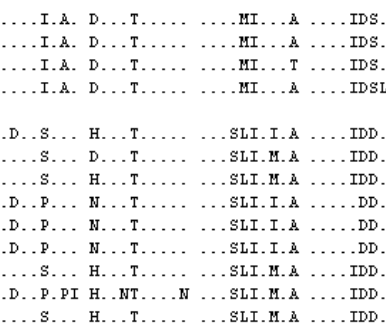

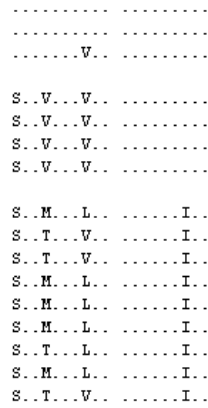

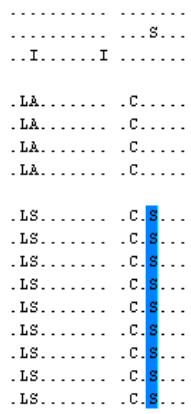

VPNDTLS--- -----YNDTT WPNDTLYSNS -------TFD FTRYIBNAEN QYFLEGSKDA LLCGNGTDAG KCPBGYLCMK AGRNPNYGYT SFDSFGWAFL ALFRLMTQDN WTESLPQLTLR AGGQTYMLFF WWIFLGSFY LINLILAWVA

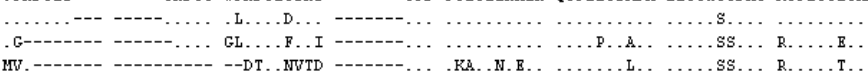

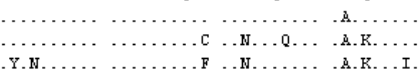

PSFTSD. LQ- ------DULW RDPLDNSTLN DNFTLTG... WH. ..... BD. F...D. AL PSFTSD. LQ- -----DVLW RDPLDNSTLN DNFTLTG... WH. W...... BD. F...D.AL

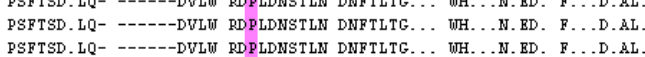

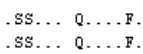

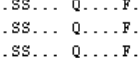

TWYGND TWG- ----G...WT GG... WTGGQB SWAGN-Y ...

TWYGND TWYY- -----G... WI YG... TIN. QR SWWSN-S. . .

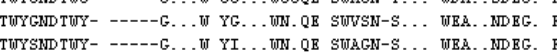

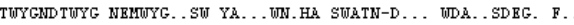

TWYGND TWYG NEMUYG. . SW YA... WNA. HA SWATQRYSLT G.L...NDEG. F......

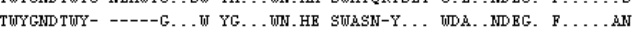

TWYSSND TWN- -----S... WI SS. . MTNN. HE SMASN-Y.

IDA. .NDEG. F.....A.

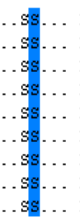

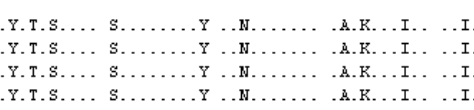

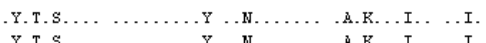

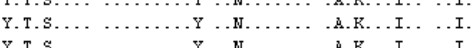

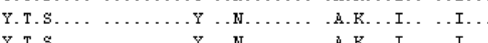

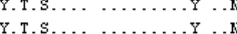

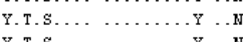

Y.T.S.

H.T.S.

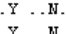

Y

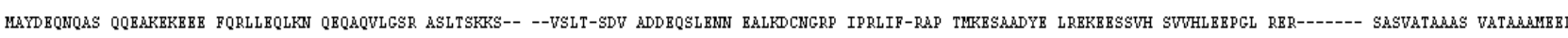
.

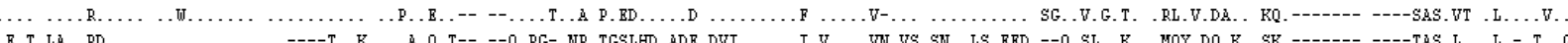

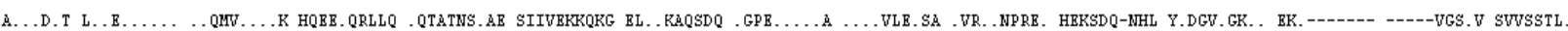

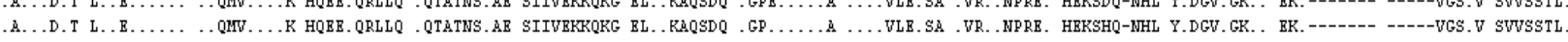

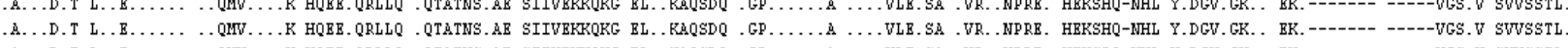

QNV .... K HQRE. QRLLQ . QTATNS. AB SIIVBKKQRG BL . KAQSDQ . GP .

A...B.T LA.DQ.

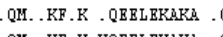

A...T.T LA.DQ

A...B.T LA.D...

A... B.T LA.D.

A... B.T LA.D.

A... B.T LA.DQ.

N.E.T LA.DQ

QM. . KF.K HOBRL RYUKS

QM. .KY.K HQEBLEKAKA

OM. KF.K HQBELLEKAKS

QM. . KF. K HQBELBKAKA . OR

QM. . KF.K HQRELEKAKA

QM. .KF.K .QBELBKAKA

OMM. KFOK . OBELBKAKA DQP
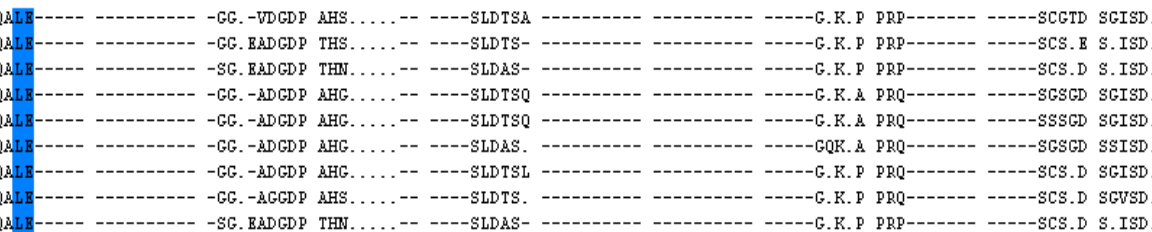

II

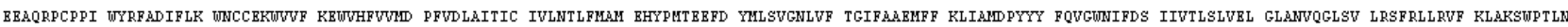

Tn

garter snakes

mammals
BLTs

Bents

Warts

WCTs

Bos

Mus

Hs 5 bin1

HsSk

Macaca

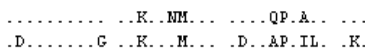

.HOK. . . W ...K. . HAV.I . ...PV. . KL . HIIKLI. I

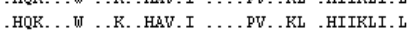

HOK. . . W ... . . HAV.I . . PV..KL . HIIKLI.

HOK... TI . . K. . HAV.I

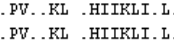

. HQK. . . W ...KCSHKV. I

.TP..K. .KI.NLI.

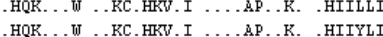

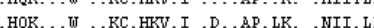

HQK. . .W . . KC.HKV.I ....AP.LK. .NII.L

. HQK... IT ..KC. HKV.I . D. . AP.MR. .NII. LI

HOK. . . W . . KC. HKV.I . ...TP.MR. .NII. LI

HQK. . . . . KC. HKV.I ......... . HIIYL

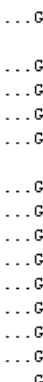

\begin{tabular}{|c|}
\hline G............ \\
\hline$G \ldots \ldots \ldots, \ldots$ \\
\hline$G \ldots \ldots \ldots, \ldots$ \\
\hline 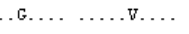 \\
\hline G.... \\
\hline$G \ldots$ \\
\hline$\cdots \cdots$ \\
\hline$\ldots \ldots$ \\
\hline $.6 \ldots$ \\
\hline$\cdots$ \\
\hline $\begin{array}{l}\ldots \ldots \ldots \\
\cdots \ldots \ldots \ldots\end{array}$ \\
\hline
\end{tabular}

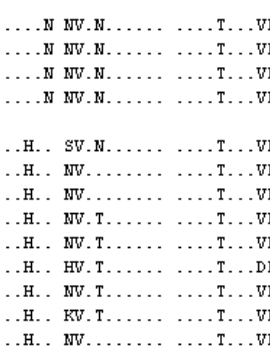

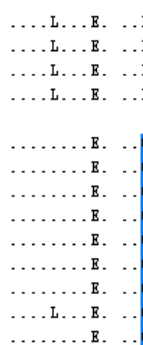

M. . 
BLTS

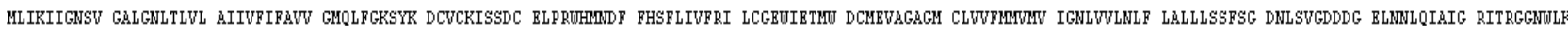

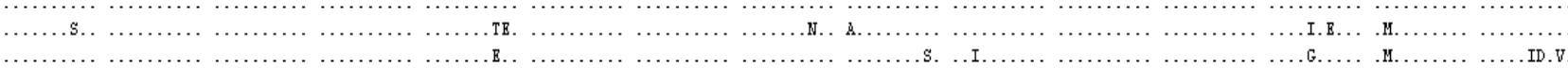

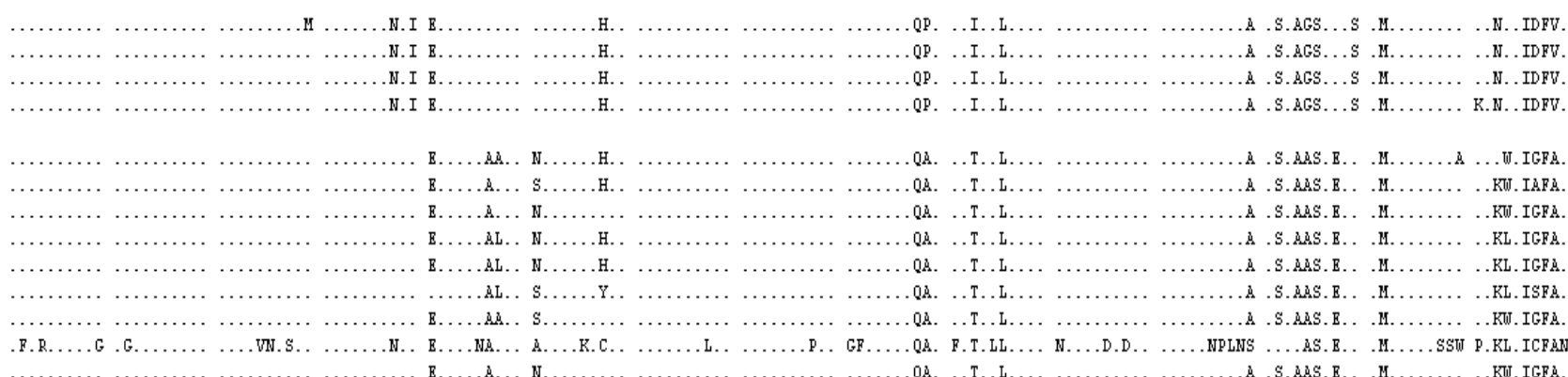

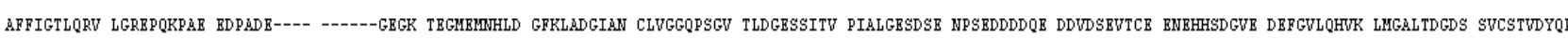

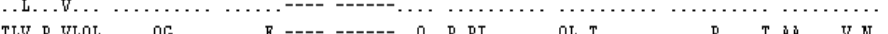

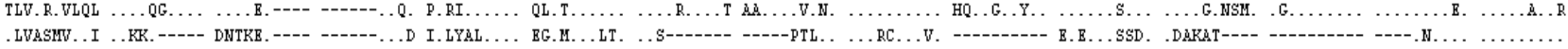

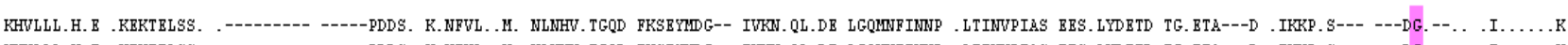
KHVLLL.H. B .KEKTELSS. --------- -----pDDS. K.NFVL. . M. NLNHV. TGQD FKSEYMDG-- IVKN. QL.DB LGQMNPINNP .LTINVPIAS BES.LYDETD TG. BTA---D .IKKP.S--- ---DG.--.. .I. .....K.

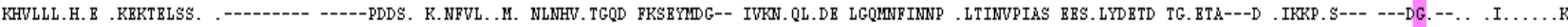

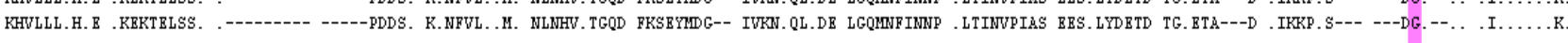

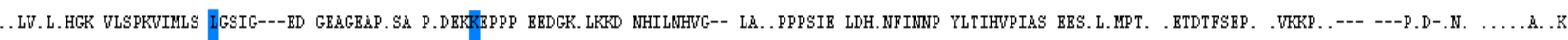

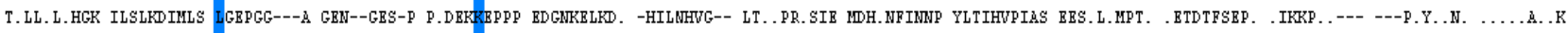

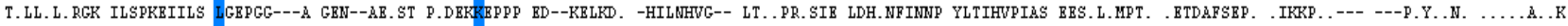

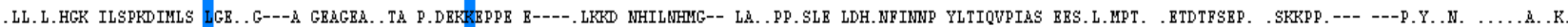

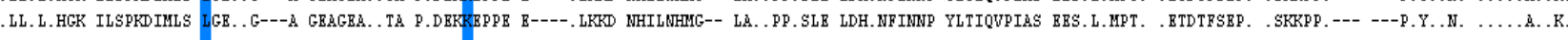

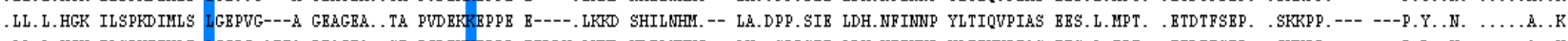

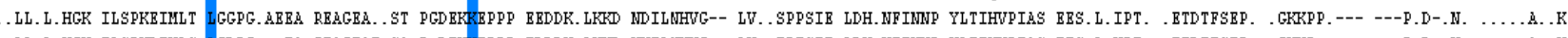

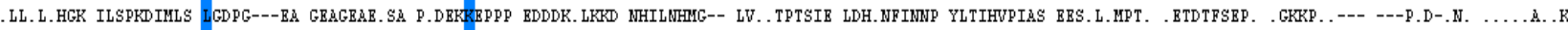

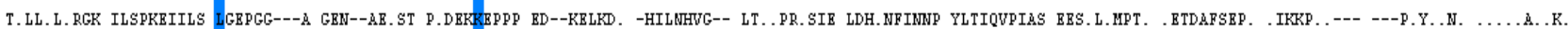

III

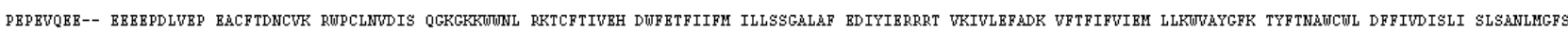

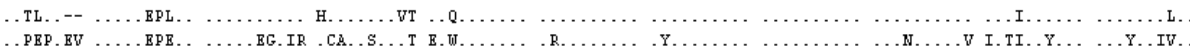

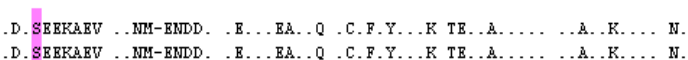

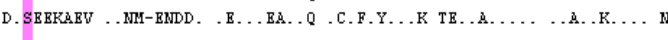

\begin{tabular}{|c|c|c|c|c|}
\hline & & & & \\
\hline & . NP & . B...EBA & & . . R.... Т. \\
\hline & . .NP-BGEQ. & . B...BA. & .C...Y. & . R. .M. . T. \\
\hline & ..NP -1 & . B...BA. . 0 &. $\mathrm{Y}$. & T. RA. \\
\hline & ..NP-BGBQ & . B...BA. . Q & $\cdots Y$ & .T. RA. \\
\hline & ..NP & . В. . BA. . Q & $\mathrm{Y}$ & .R....T. RA. \\
\hline & ..NP-EGEQ & . B...BA. Q & .C.F.Y. & . R. M. T. RA. \\
\hline & & 1. & & . R. M. T. \\
\hline & & & & \\
\hline
\end{tabular}

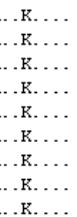

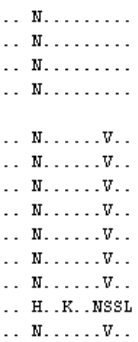

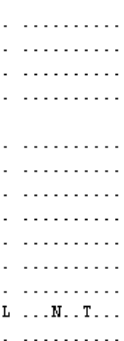

.H. IRTI..Y... I..YV.IL

.H. IRTI... Y... I..YV.IL

H. Q. V IRTI..Y....... Y..IL.

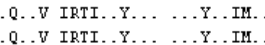

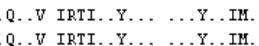

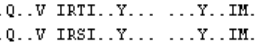
Q..V IRTI..Y... ...Y. . IM. Q.V IRTI..Y.......... . IL
.H. IRTI... Y... I...YV.IL . . Q..V IOTI..Y.......... IL Q..V IRTI..Y... ...Y...IL

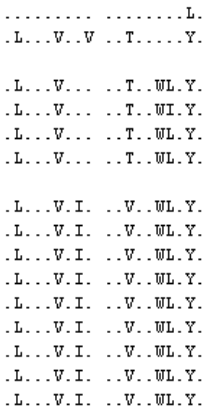

BLTs

BenTs

Bents
WarTs

WCTs

Bos
Mus

Mus

HsSkM

$\mathrm{Hs}$

Hacaca

$\mathrm{Cf}$

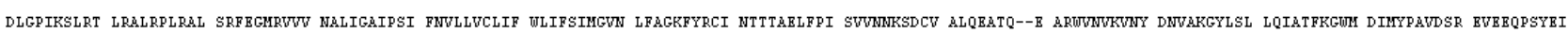
$\begin{array}{llllll}\ldots & \end{array}$

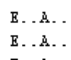

B.............

E.
B.
B..
B..
B..
B.
B.
B.
B.

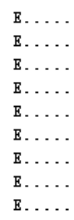

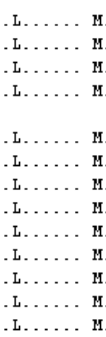

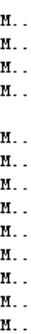

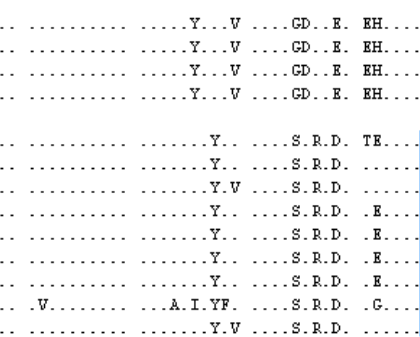

..I N. INIBNATD $v$.

I N. INIBNATD $\mathrm{V}$

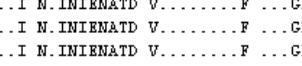

B. B S.MHTG---Q V...L.
B. B S.MYTG---0 V. . M.

... S.MYTG---Q V...M

B. B S.MHTG---Q V. .L

B. S S.MHTG---Q V..L

B. B S. MHTG---0 V.. L

B. B S. MHTG---0 V. . L

B. B S. IHTG---0 V.. L
ESB S. MYTG---0 V. 
garter snakes

mammals

\section{$\operatorname{Tp}$}

ELTs
BenTs
WarTs

TarTs

Bos
Mus

Fnslinl

$\mathrm{H}=5 \mathrm{kH} \mathrm{HL}$

$\mathrm{Hs}$

Thaces

Ec

garter snakes

$L T \equiv$

BenT:
TIarT
TUCT

Bos

Mus
Fns:min1
Hs:kH1

Hs SknI
Hs

Macaca
Cf

$\mathrm{BC}$
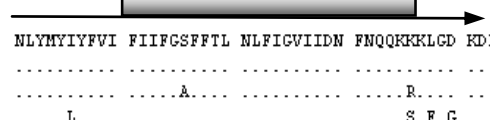

\section{IFHT}

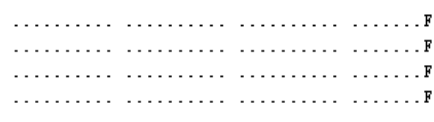

F. G $\ldots \ldots \ldots \ldots$

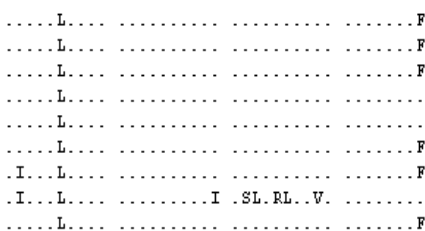

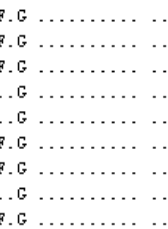

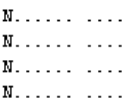

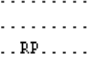
T...... S.

\begin{tabular}{|c|c|}
\hline T...NI. & VT . . \\
\hline $\mathrm{O} . \mathrm{KY} . \mathrm{NI}$ & UT _ . \\
\hline Q.KN..MI. & .VT_... \\
\hline I.KY. . MII. & VT ... \\
\hline I.KN. . H.Y Y & LVTK. \\
\hline Q.K. . . H.Y & WTK. W. \\
\hline Q.K...M.Y & VIK.V. \\
\hline $\mathrm{O} . \mathrm{K} \ldots \mathrm{H}, \mathrm{Y}$ & LUTK. \\
\hline Q.K...M.Y & LVTK. $\mathbf{A}$. \\
\hline Q.K...M.Y & LVTK. $\mathbf{A}$. \\
\hline Q.K...Y.Y & CUTK. W. \\
\hline K. . .M.Y & . VTK.T. \\
\hline II. & UTK. W \\
\hline
\end{tabular}

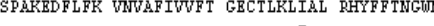

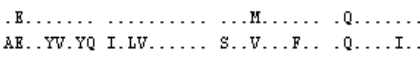
.QT.ITI.AQ I.LW..II.. S..I..M. . QT ITI. AQ I. LT . II . S . F . MY . QI.ITI.AO I.LW..II.. S......M. QT. ITI.AQ I.LW..II. S.....M.

OLLV.I.M I.MT..II. DL. U.I.YN I. MW . I QL.V.I.W I.MT . II . DL.V.I. MI I. MI . . II

. DL.V.I.MI I.MI..II QL.V.I.WN I.MI...II QL.V.I.YN I.MI..II QL.V.I.M I.MT... I. -QL. U. I. YN I.MT . II

. V. .ML.. - Q.Y. . T.

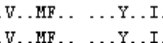

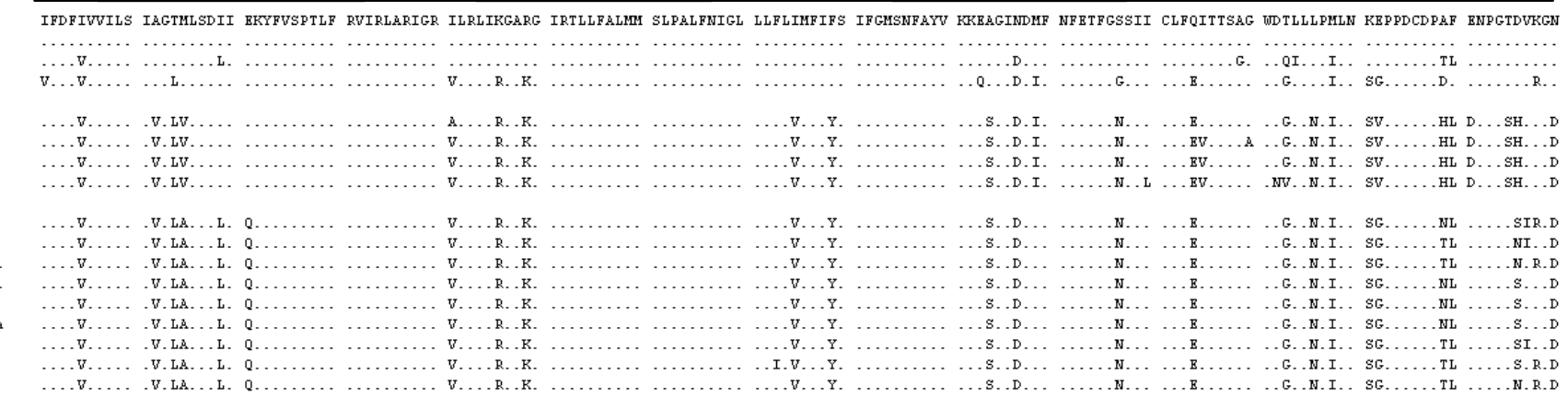

$\mathrm{Tp}_{p}$
$\mathrm{Ir}$
$\mathrm{Tr}$
$\mathrm{Dr}$

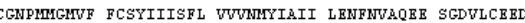

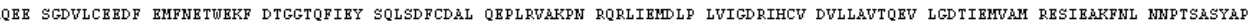
…......

BLTs

Bents
Wart $\mathrm{T}$
WCT $=$

S. . It …. I.

mammals

Bos

Prskin

HSBkMI

Hs
Macaca

Ec

Tp

$\mathrm{Tn}$

garter snakes

BLTs

BenTs

$\operatorname{tar} \mathrm{T}$

WCTs

Bos

Mus

HsSkM1

$\mathrm{Hs}$

Macaca

$\mathrm{BC}$

.SI.IC.
SI.IC.
SI.IC.
SI.IC.
SI.IC.
SI.IC.
SI.IC.
SI.IC.
SI.IC.

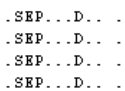

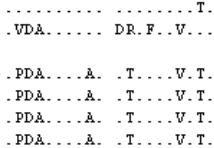

SEF. G.D.
SEF . .D.

SEP.S.D.

SEP.G.D.
SEP.G.D.

SEP.G.D.

SEP.G.D

SEE.S.D.

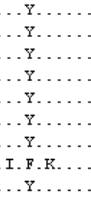

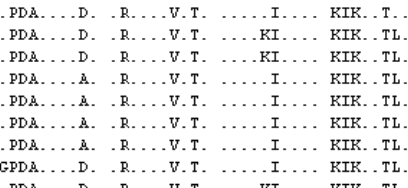

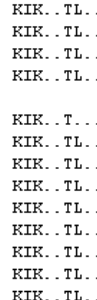

M. P. . F. . L I I. F. L . F

H. F. . F . I I I. F - L . F

SG. .D. L KQ. M. B. . MA A. . SEW . . E SG. D. L RQ. H. E. MA A. . BRV - E

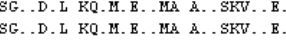

M.P.F.I.I I.F.L.R. SE. D.L R. TH. E. . LA A. SER . E M.P..K..I .I.F.L.E. SE. D. L KOTM. E. . HQ A. . SEW. . E.

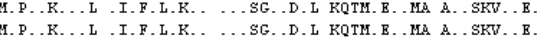

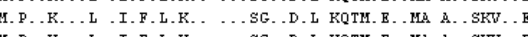

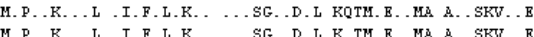

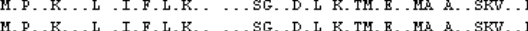

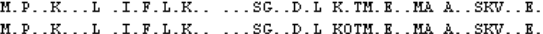

ITTTURQKER DMBAWUIQRA YRNHLHKRGI HHAMYIQRSK -TGRKAMTED APEKBGLLAQ KMGALYGSDA DLABEVRGLR R--RPD--PQ T--RCSGARC SPEPPEPN-I ILVPVRITNB LLLHSAPSQQ --------SSP TQTILRETNV

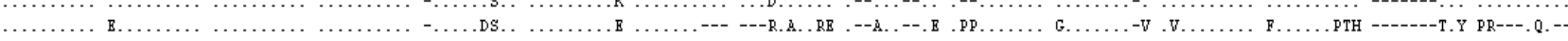

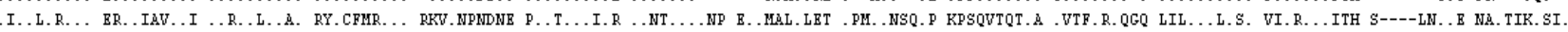

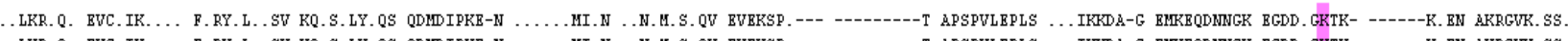

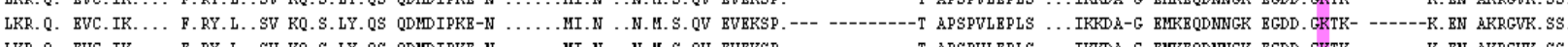

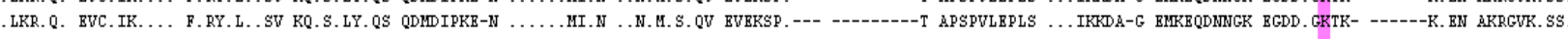

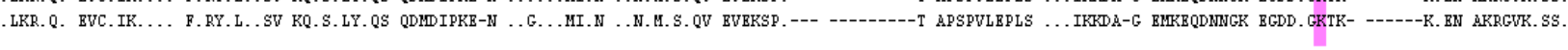

.R. .LQ.SV KQ.S.MY.HN H--DGGRG-G

I.D T. SKV..--- -PDNGNS--

LKR.Q. BVC.IK. .

R..LQ.SV KQ.S.MY. HN H--DGGRG-G

R. LQ.SV KQ.S.MY.HS Q--DGNGD-G

.N T. NKH. . --- - SEK.DN-

LKR. Q. BVC.IK.

LKR. H. EVC. IK.

R. .LQ.SM KQ.S.MY.HS H--DGSGD-

.N T. SKM. .-- -HENGNS

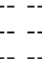
G VPSKR-BR.G .TGD.G.A-H G.R.ISPSDA P.PPAP. L-- ------GQT VRPGUK.SL LKR.H. BVC.IK.... .....LQ.SV KQ.S.MY.HS H-DGSGD-

$--$
G VQSQGEBEKA .T.DAG.T-V BPK.TSSSDT A.TP. P. PLP PSSSPPQGQT VRPGVK. SI

Figure S1 Alignment of the complete sequence of $\mathrm{Na}_{\mathrm{v}} 1.4$ channels from pufferfish, garter snakes and mammals.

The alignment was constructed with Clustal W implemented in MEGA 4.0. Predicted four domains and the secondary structure of each domain are indicated at the top of the sequences. Deduced amino acid sequence of the rat sodium channel that shows the putative six transmembrane segments of each domain is marked as rectangle. Sites under positive selection are highlighted in purple and blue. 